Revista del Centro de Investigación de la Universidad La Salle

Vol. 14, No. 56, Julio-Diciembre, 2021: 87-112

DOI: http://doi.org/10.26457/recein.v14i56.2857

\title{
Implicaciones del microbioma en la etiología y el tratamiento del cáncer de próstata en humanos
}

\section{Implications of the microbiome in the etiology and treatment of prostate cancer in humans}

\author{
Lina Paola Flores-Martínez \\ Facultad de Medicina Veterinaria y Zootecnia, UNAM (México) \\ Isaac G-Santoyo \\ Facultad de Psicología, UNAM (México) \\ Cristian Arriaga-Canon \\ Instituto Nacional de Cancerología (México) \\ Francisco Javier Jiménez-Trejo* \\ Instituto Nacional de Pediatría (México) \\ Miguel Tapia Rodríguez ${ }^{* *}$ \\ Instituto de Investigaciones Biomédicas, UNAM (México)
}

Recibido: 15 de enero de 2021

Aceptado: 03 de abril de 2021

Publicado: 10 de noviembre de 2021

\section{Resumen}

El cuerpo humano está habitado por células microbianas que coexisten equilibrada y armónicamente en diversos órganos participando en su correcto funcionamiento. Si la proporción de estos microorganismos es alterada de manera significativa, pueden ocurrir disfunciones metabólicas, fisiológicas y/o inmunológicas que repercutan en todo el organismo, llegando a ocasionar o a agravar procesos inflamatorios o incluso, carcinogénicos. En la presente revisión se abordarán aspectos importantes para explicar la naturaleza, así como las causas del desequilibrio de estos microorganismos, se describirán las especies involucradas conocidas; así como su influencia sobre el cáncer, particularmente el de próstata. De igual manera, se describirá el efecto de la modulación del microbioma sobre los diversos protocolos terapéu-

*Email: trejofj@hotmail.com

${ }^{* *}$ Email: mtapia@biomedicas.unam.mx

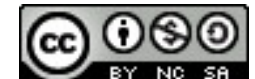

Revista del Centro de Investigación. Universidad La Salle por Dirección de Investigación. Universidad La Salle Ciudad de México se distribuye bajo una Licencia Creative Commons Atribución-NoComercial-CompartirIgual 
Flores-Martínez, L. P.; G-Santoyo, I. ; Arriaga-Canon, C.; Jiménez-Trejo, F. J.; Tapia Rodríguez, M.

ticos actuales aplicados a pacientes que padecen cáncer como son la quimioterapia, radioterapia e inmunoterapia. Finalmente, se describirán las nuevas terapias experimentales que actúan en cooperación con el microbioma para combatir de una mejor manera este importante padecimiento.

Palabras clave: Microbioma, Cáncer de Próstata, Disbiosis, Inflamación, Terapia experimental, Hologenoma. 


\section{Abstract}

The human body is inhabited by microbial cells which coexist balanced and harmoniously in several organs, participating on its proper functions; this large number of microorganisms is known as the human hologenome. If their delicate proportion is altered, metabolic, physiological or immunological dysfunctions appears and they could be spread to the whole organism; causing or aggravating inflammatory or even carcinogenic processes. The present review will be focused on important aspects about the nature, as well as the causes of the imbalance of these microorganisms, the known species involved as well as their influence on cancer, particularly prostate cancer. The effect of microbiome modulation on some of the current therapeutic protocols applied to cancer patients such as chemotherapy, radiation therapy and immunotherapy also will be described. Finally, we will discuss the new experimental cancer therapies that act in cooperation with the microbiome.

Keywords: Microbiome, Hologenome, Prostate Cancer, Dysbiosis, Inflammation, Experimental Therapy 
Flores-Martínez, L. P.; G-Santoyo, I.; Arriaga-Canon, C.; Jiménez-Trejo, F. J.; Tapia Rodríguez, M.

\section{Introducción}

A lo largo de la evolución, los seres humanos -como muchos otros seres vivos que habitan nuestro planeta- hemos tenido diferentes especies aliadas; entre éstas podemos mencionar algunas poblaciones de seres microscópicos tales como bacterias, virus, hongos o arqueas, que cohabitan en nuestro interior y que en condiciones de salud contribuyen a un estado de equilibrio en el que ambos nos beneficiamos; a este conjunto diverso de microorganismos junto con su microambiente, sus metabolitos producidos y su metagenoma se le conoce como microbioma y actualmente sabemos que son poblaciones muy dinámicas y que están presentes en diversos órganos y sistemas tales como el tracto gastrointestinal, sistema genitourinario, piel y cavidad oral, entre otros. Los microbiomas han contribuido en la generación de la homeostasis durante el desarrollo, crecimiento y supervivencia de un vasto número de organismos vivos complejos, tanto vegetales como animales, dando sustento al concepto de hologenoma (Davenport y et al, 2017; Rosenberg y Zilber-Rosenberg, 2019; Sanchez-Cañizares y et al, 2017).

Es probable que esta relación: 1) haya sido establecida desde hace mucho tiempo; 2) haya contribuido a la constante evolución de las especies y 3 ) haya asegurado la permanencia de estas últimas en la Tierra hasta la actualidad. Se ha postulado que los microorganismos iniciaron su presencia antes del desarrollo de las células eucariotas, con lo cual fueron encontrando su equilibrio para trabajar en simbiosis incluso antes de la aparición de organismos complejos (Groussin y et al, 2020). No obstante, lo anterior, si al interior del microbioma ocurren alteraciones importantes en su número, así como en poblaciones alrededor de sus nichos, pueden llegar a promover e/o iniciar una enfermedad en el hospedero generando una disbiosis, la cual es el desequilibrio entre las bacterias protectoras y patógenas del tracto digestivo (ver más adelante; Brown y et al, 2019; Feng et al, 2019). Si este equilibrio es alterado, puede llegar a asociarse a diversos factores estresantes como enfermedades, edad, dieta o algunos otros factores ambientales y contribuir a romper la homeostasis del hospedero.

Comprender el equilibrio dinámico de estos nichos se ha vuelto crítico para descifrar el papel que tiene el microbioma en el proceso de muchas patologías; dentro de la amplia gama de enfermedades en las que pueden estar involucrados estos microorganismos, sumado a otros factores anteriormente mencionados se encuentran distintos tipos de cáncer (ver más adelante; Goodman y Gardner, 2018; Katongole y et al, 2020). El cáncer es una enfermedad compleja multifactorial iniciada por un grupo de células que se multiplican sin control y de manera autónoma, invadiendo regiones tisulares adyacentes y en ciertas condiciones, otros tejidos, órganos o sistemas. En condiciones normales, la mayoría de las células se dividen y mueren durante un periodo de tiempo programado. Sin embargo, la célula cancerosa o tumoral "pierde" la capacidad para realizar la muerte celular programada (apoptosis) y se divide casi sin límite; tal multiplicación en el número de células llega a formar masas celulares denominadas "tumores" o "neoplasias", que en su expansión pueden destruir y sustituir a los tejidos normales y en caso de ser malignos derivar hasta tornarse cáncer (Puente, 2019, de la Garza y Juárez-Sánchez, 2014). En los últimos años, diversos estudios han aportado evidencia de que la conformación del microbioma tiene un papel importante en el desarrollo de algunos tipos de cáncer, tales como los de mama, pulmón, cérvico uterino, estómago, hígado, ovarios y próstata (Katongole y et al, 2020; Nicolaro y et al, 2020; Ohadian Moghadam S. y Ali Momeni S., 2020; Porter y et al, 2018); en la presente revisión nos enfocaremos en 
este último, neoplasia maligna masculina más común y la segunda en importancia de letalidad en hombres a nivel mundial (Feng y et al, 2019; Katongole y et al, 2020; Ohadian Moghadam S. y Ali Momeni S., 2020). En el 2018, se diagnosticaron aproximadamente 3.8 millones de casos y 1.4 millones de personas murieron por los diferentes tipos de cáncer existentes. Alrededor de $57 \%$ de los casos y $47 \%$ de las muertes debidas al cáncer ocurrieron en personas de 69 años o menos. En México, se estima que al año se diagnostican 190,000 nuevos casos de cáncer de los cuales aproximadamente 13\% corresponde a cáncer de próstata, con una tasa de mortalidad del 8\% (Knaul y et al, 2009; GloboCan, 2020; figura 1); dado este panorama resulta de suma importancia conocer todos los procesos implicados en el desarrollo de este padecimiento, por lo que en el presente trabajo se describirá más a fondo su correlación con el microbioma y la disbiosis asociada a factores extrínsecos tales como la dieta y el estilo de vida de los individuos afectados.

Figura 1

Incidencia de cáncer en México en la población total en 2020

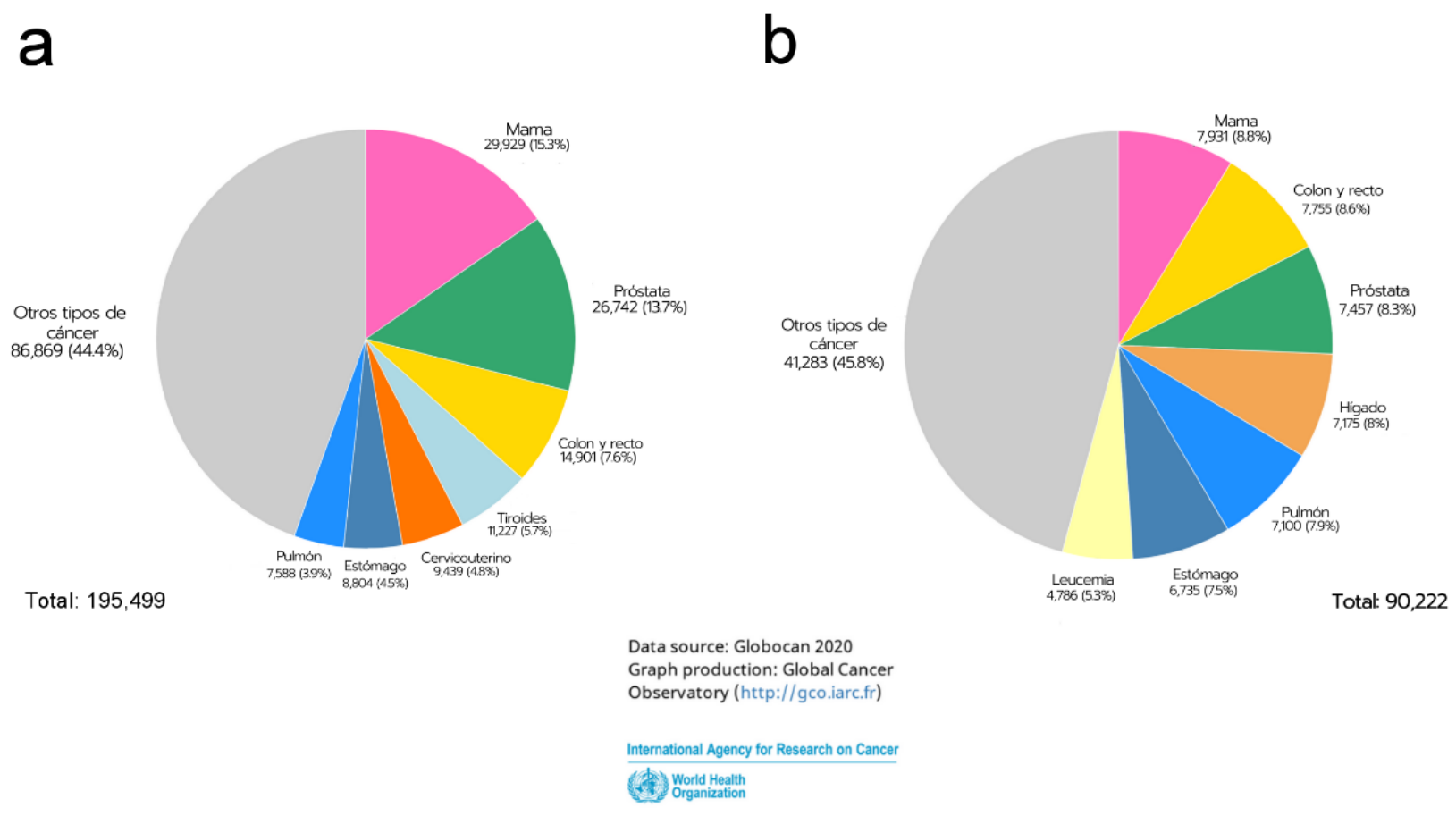

a) Número estimado de casos nuevos, b). Número estimado de mortalidad. Datos: Globocan, Gráficos: Global Cancer Observatory, International Agency for Research in Cancer, World Health Organization. Modificado de https://gco.iarc.fr/ 
Flores-Martínez, L. P.; G-Santoyo, I. ; Arriaga-Canon, C.; Jiménez-Trejo, F. J.; Tapia Rodríguez, M.

\section{Microbioma humano}

Todos los seres humanos albergan entre 10 y 100 billones de microorganismos en una relación simbiótica (Sender y et al, 2016; Rosenberg y Zilber-Rosenberg, 2019). Esto beneficia tanto a los microbios como a sus anfitriones, siempre y cuando el organismo se encuentre en un estado saludable. El microbioma humano es esencial para la regulación de la homeostasis, el metabolismo e incluso para el correcto funcionamiento de diferentes órganos; desempeña un papel clave en la digestión y en la defensa inmunitaria del hospedero, además de que influye en las funciones endocrinas, en la hematopoyesis, la inflamación y el metabolismo, afectando incluso al sistema nervioso central (Brown y et al, 2019; Jacobson y et al, 2021; Zhang y et al, 2019). Debido a que es un ecosistema dinámico que contiene miles de taxones con procesos y comportamientos metabólicos únicos, es importante caracterizarlo, así como a sus diferentes alteraciones para conocer su impacto en los estados patológicos del hospedero (Dutta y Lim, 2020).

Mediante análisis de secuencias ribosomales se ha descrito la presencia de trece filos bacterianos en la mucosa gastrointestinal humana: Firmicutes, Bacteroidetes, Proteobacteria, Actinobacteria, Verrucomicrobia, Spyrochaetes, Fusobacteria, Deferribacteres, Cyanobacteria, Planctomycetes, Lentisphaerae, TM7 y Tenericutes, de los cuales, el 65\% de la población descrita corresponde al filo Firmicutes, y el 30\% a Bacteroidetes; los géneros anaerobios más comunes reportados son Bacteroides, Eubacterium, Bifidobacterium, Peptostreptococcus, Fusobacterium, Clostridium y Ruminococcus (Yang y et al, 2009). Las estimaciones varían, pero se ha descrito que podría haber más de 5000 géneros diferentes de microorganismos conformando el microbioma humano (Falony y et al, 2016, Rojo y et al, 2017); en adición a lo anterior, se ha reportado que en condiciones de "buena salud" existe una gran diversidad individual en la composición del hologenoma humano por lo que no es posible definir un estándar de "microbioma saludable" (Lloyd-Price y et al, 2016; Yang y et al, 2009). La composición del microbioma de cada individuo depende de varios factores que le son inherentes, tales como la colonización al nacer, cambios derivados del envejecimiento del organismo, la presencia de enfermedades o adicciones, niveles de ejercicio físico, dieta, e incluso el estilo de vida y la localización geográfica (Rosenberg y Zilber-Rosenberg, 2019; Sánchez-Quinto y et al, 2020); como dato interesante, dentro del microbioma existe una diversidad en las propiedades catalíticas de enzimas ortólogas, lo cual le otorga una diversidad funcional que puede resultar importante para la supervivencia del hospedero (Wallace et al, 2015).

El epitelio gastrointestinal es el principal encargado de mantener una correcta proporción de los microorganismos que pueden colonizar el tracto gastrointestinal; esto lo realiza principalmente a través de 1) la secreción de moco en el cual se pueden encontrar glicoproteínas tales como MUC2, las cuales constituyen una barrera física que impide el paso de los microorganismos hacia el interior del tracto pero al mismo tiempo les provee de nutrientes para permitir su colonización, o péptidos como el péptido antimicrobiano (AMPs), sIgA específico de microbiota, IL-17A e IL-22, los cuales mantienen la selectividad a ciertas especies sobre otras; y 2) la presencia de placas de Peyer, células presentadoras de antígeno, linfocitos B y $\mathrm{T}$ localizados en la lámina propria situada entre la mucosa y el epitelio gastrointestinal (Brown y et al, 2019). Por su parte las bacterias simbiontes secretan distintas moléculas dentro de estructuras conocidas como vesículas membranales bacterianas hacia el tracto gastrointestinal, entre las cuales 
se encuentran el peptidoglicano, polisacárido A y lipopolisacárido que se encargan de activar la respuesta inmune innata del tracto, y ácidos grasos de cadena corta (AGCC) como el propionato y butirato, los cuales contribuyen a la conformación de la barrera evitando la unión entre microorganismos y células epiteliales. El butirato ayuda a mantener una condición anaeróbica en la luz intestinal necesaria para la preservación de anaerobios obligados, este conjunto de moléculas determina la composición y distribución del microbioma presente como por ejemplo, sólo Clostridium, Lactobacillus y Enterococcus están enriquecidos tanto en la superficie epitelial como en la mucosa mientras que Bacteroides, Bifidobacterium, Streptococcus, Enterobacter, Enterococcus, Clostridium y Lactobacillus son predominantes en la luz intestinal (Telesford y et al, 2015; Dutta y Lim, 2020; Johnston y et al, 2021).

\section{Disbiosis}

La disbiosis intestinal ocurre cuando hay alteraciones en la proporción de microorganismos inocuos y potencialmente perjudiciales junto con cambios en su diversidad y densidad poblacional (Guarner, 2016). Estos cambios conducen a una disminución en el grosor de la capa de moco ubicada a lo largo del tracto digestivo, lo que conlleva a una disminución en la defensa antimicrobiana y alteraciones en la permeabilidad del epitelio. Esto a su vez deriva en una mayor translocación de bacterias y productos bacterianos intestinales en la circulación sistémica, lo cual puede desencadenar procesos inflamatorios y modificaciones en la respuesta inmune. En este sentido, se ha reportado la asociación de disbiosis con al menos 105 padecimientos humanos diferentes, incluidos diversos tipos de cáncer (Brown y et al, 2019, Dutta y Lim, 2020 Rojo y et al, 2017). De manera interesante, los géneros Streptococcus, Staphylococcus, Enterococcus, Clostridium, Lactobacillus, Faecalibacterium y Veillonella (filo Firmicutes), Prevotella y Bacteroides (filo Bacteroidetes), Bifidobacterium (filo Actinobacteria), Escherichia (filo Proteobacteria) y Fusobacterium (filo Fusobacteria) son los más susceptibles a modificaciones, ya que se ha reportado que alteraciones en sus poblaciones están asociadas con al menos el 50\% de los desórdenes o enfermedades relacionadas a la microbiota (Rojo y et al, 2017).

La disbiosis intestinal puede causar hipoxia epitelial, lo que causa un incremento en la oxigenación de la superficie de la mucosa que afecta a los microorganismos anaerobios obligados; algunos de estos como las proteobacterias producen genotoxinas como la colibactina y la toxina de distensión citoletal (CDT) que puede inducir un estado de inflamación y daño en el ADN en células de diversos órganos, modificando algunas señalizaciones, como el caso de la apoptosis, lo cual puede propiciar el desarrollo de neoplasias y, potencialmente, derivar a cáncer (Dutta y Lim, 2020). Así mismo puede disminuir el grosor de la capa de moco lo cual reduce la producción de ácidos grasos de cadena corta y daña la barrera de la mucosa, lo que promueve que los patrones moleculares asociados a patógenos (Pathogen-associated molecular patterns, PAMPs) de diferentes bacterias no sean reconocidos, permitiendo que causen daño al hospedero. Finalmente, se conoce que los cambios en la composición y densidad microbiana desencadenan la liberación epitelial de patrones moleculares asociados al daño (Damage-associated molecular patterns, DAMPs) tales como adenosín trifosfato celular, calreticulina citoplasmática, ácidos nucleicos endógenos y proteínas intracelulares, los cuales interactuarían con los receptores de patrones de reconocimiento celular (Pattern recognition receptors; PRR), cuya activación desencadena una condición proinflamatoria que causa daño tisular e inflamación local (Rai, 2020). 
Flores-Martínez, L. P.; G-Santoyo, I. ; Arriaga-Canon, C.; Jiménez-Trejo, F. J.; Tapia Rodríguez, M.

\section{Cáncer}

Cada uno de los seres humanos funcionamos a través de un número determinado de células eucariotas (equivalente al de la microbiota, 10 y 100 billones; Sender y et al, 2016), las cuales son las unidades básicas funcionales que desempeñan funciones particulares en el organismo dependientes de su entorno, pero comprometidas a partir de su célula precursora. En un entorno normal cada una de estas crece y se divide de manera coordinada y ordenada, sin embargo hay ocasiones en que este proceso es alterado, y el material genético contenido en el ADN de una o varias células sufre un gran daño o alteración sin poder ser reparado correctamente, lo cual deriva en cambios (mutaciones) irreversibles en genes específicos que regulan el crecimiento, la muerte y principalmente, la división normal de las células, dando inicio a una replicación irregular, autónoma y descontrolada. Cuando esto ocurre, las células no mueren cuando deberían (no entran a muerte celular programada) y se comienzan a replicar en células nuevas que el organismo no necesita; estas "nuevas" células se multiplican de manera acelerada y sin patrón estructural, y generan una masa de tejido inicialmente compacto, conocida como tumor, el cual puede ser una lesión considerada benigna (adenoma, sin propagación a otros tejidos) o maligna (carcinoma o sarcoma, figura 2). Los tumores malignos son de rápido crecimiento; no inhiben su crecimiento por contacto, se propagan tempranamente a otros tejidos, reaparecen con frecuencia tras ser extirpados y provocan la muerte en un periodo variable de tiempo, si no se realiza tratamiento alguno. El grado de malignidad del cáncer es variable, básicamente depende de la agresividad de sus células y características biológicas. Son capaces de diseminarse y provocar metástasis (anidarse) en órganos y tejidos distantes. Su velocidad de crecimiento va más allá de los límites normales y, sus vías de diseminación pueden ser a través del sistema linfático (diseminación linfática) o circulatorio (diseminación hemática), o por extensión e invasión directa a los tejidos vecinos. Actualmente, se conocen más de 200 tipos diferentes de cáncer dependiendo del tejido del que se deriven. Los más frecuentes son los de piel, pulmón, mama, colon, recto y próstata (Puente y de Velasco, 2019). 
Figura 2

Proliferación celular en condiciones normales y condiciones carcinogénicas.

a
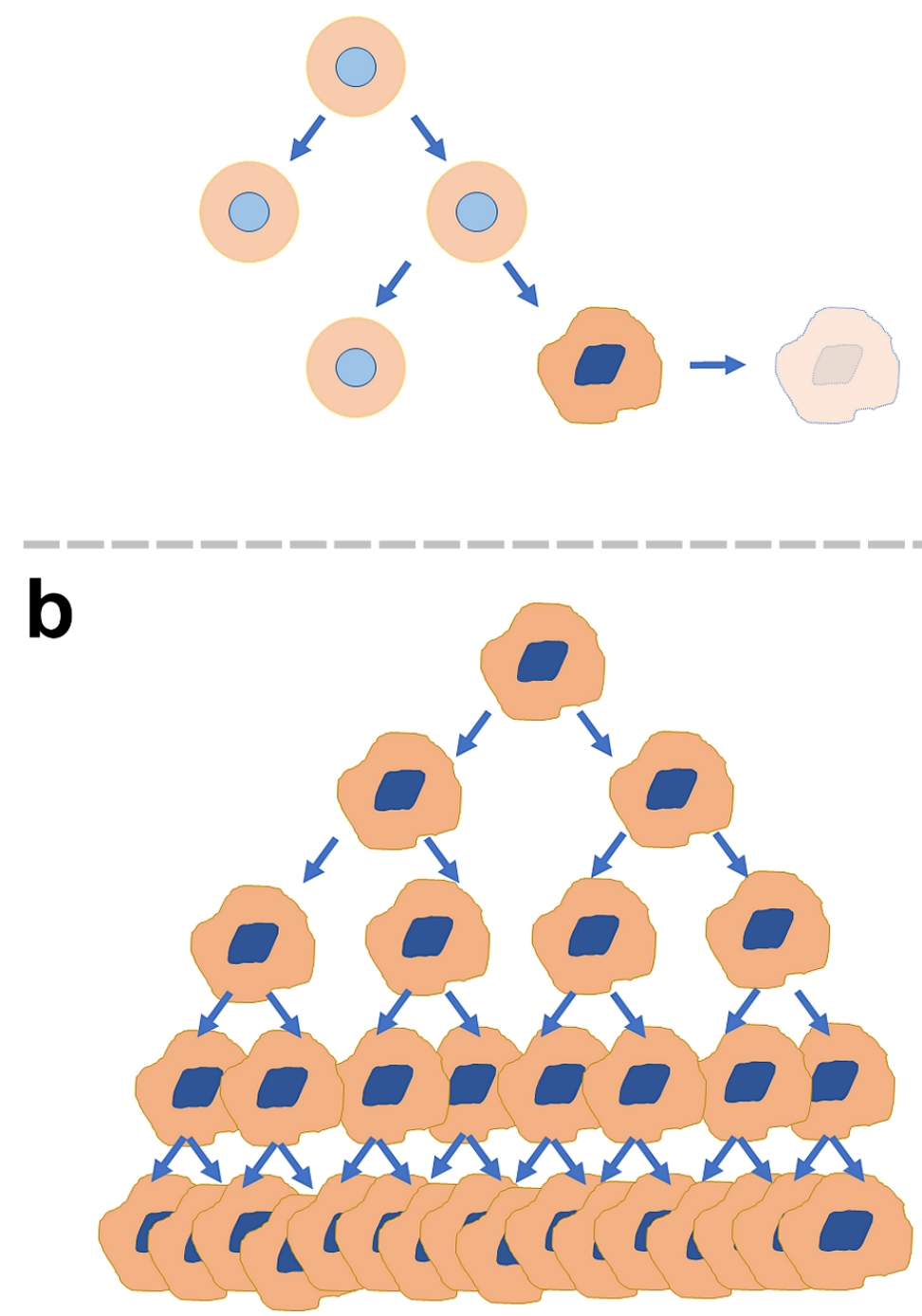

\section{Célula normal \\ Célula cancerosa}

a). Células dividiéndose de manera normal y controlada (indicadas en el esquema); en condiciones normales, si una de ellas desarrolla alguna alteración es eliminada mediante el proceso de muerte celular programada; b) condición anormal donde una célula cancerosa que no pudo ser eliminada por el organismo continúa replicándose sin control y de manera acelerada, generando inicialmente una hiperplasia. Adaptado de Puente, J., de Velasco, G. (2019). 
Se han descrito una serie de etapas necesarias en la carcinogénesis, las cuales se desarrollan en un lapso variable. El primer paso consiste en la acción de un agente iniciador, que induce una o varias mutaciones en el DNA; en ocasiones se nace con esta mutación y en otras se induce por factores internos, tales como hormonas, infecciones o inflamación crónica, o externos tales como exposición continua a antibióticos, exposición a rayos ionizantes, malos hábitos; consumo de cigarro y/o alcohol en exceso, etc. El segundo paso es inducido por la exposición a un agente promotor, que, aprovechando la ventaja proliferativa otorgada por el primer paso, estimula las células a dividirse. Finalmente puede existir un tercer paso donde se pueden generar nuevas mutaciones o cambios epigenéticos (metilación del ADN, modificación de las histonas), que confieren capacidades invasivas y metastásicas. (Puente y de Velasco, 2019). La etiología de los distintos tipos de cáncer ha sido muy explorada a lo largo del tiempo, y a través de numerosos estudios se han encontrado factores de riesgo tanto ambientales como genéticos estrechamente relacionados a tipos particulares de cáncer; por ejemplo, el consumo de tabaco es el principal factor de riesgo para el cáncer de pulmón, laringe y lengua, así como la sobreexposición prolongada crónica a la luz solar sin protección UV está altamente vinculada con el cáncer de piel (de la Garza Salazar y Juárez Sánchez, 2014). Con relación al papel del microbioma en la etiología del cáncer, se ha reportado que los microorganismos intestinales pueden influir en la carcinogénesis tanto local como distante (colon, hepatobiliar, pancreático, pulmón y hemático); 1) a través de infecciones y productos microbianos, 2) debido a cambios en el metabolismo de los productos producidos por el hospedero y los microorganismos o 3) mediante la modulación de la vigilancia inmunológica tumoral. Esto puede derivar en una alteración del equilibrio entre la tasa de proliferación celular y la apoptosis, desencadenando inflamación crónica y/o inmunosupresión (Dutta y Lim, 2020). Algunos estudios han mostrado que ciertos patógenos microbianos promueven la tumorogénesis en el 15 al 20\% de los casos del desarrollo de cáncer. Además de que la microbiota puede alterar la susceptibilidad y la progresión del cáncer mediante diversos mecanismos, tales como la modulación de la inflamación, inducción de daño al ADN y producción de metabolitos implicados en la oncogénesis (Bhatt y et al, 2017).

\section{Cáncer de próstata}

El cáncer de próstata es el segundo cáncer más común entre los hombres en todo el mundo. En 2018, el informe del Observatorio Global del Cáncer (Global Cancer Incidence, Mortality and Prevalence, Globocan) reportó 1'276,106 casos nuevos de cáncer de próstata, con aproximadamente 358,989 muertes por la misma enfermedad. Generalmente la mortalidad está relacionada con el desarrollo de cáncer metastásico en estadios avanzados de la enfermedad y como consecuencia de una falta de diagnóstico oportuno (Attard y et al, 2016). Con relación a su etiología, se ha observado una alta incidencia en individuos con historia familiar de cualquier tipo de cáncer, mutaciones en genes de enzimas de reparación de daño al ADN tales como BRCA1, BRCA2, ATM, ATR, NBS1, MSH2, MSH6, PMS2, CHEK2, RAD51D y PALB2, proteínas involucradas en el crecimiento y proliferación celular tales como RB1, MYC, TP53, PTEN, FOXA1, o el receptor a andrógenos (AR). Adicionalmente, otras causas como el sobrepeso, e infecciones prostáticas o del tracto urinario en general también se encuentran asociadas, ya que éstas últimas proporcionan un nicho crucial para la exposición inflamatoria repetida al microambiente prostático que conduce a lesiones precursoras 
del cáncer de próstata. Estas lesiones pueden derivar en atrofia inflamatoria proliferativa, la cual es un fenotipo intermedio propenso a alteraciones genómicas y epigenéticas (metilación del ADN, modificación de histonas) que conducen a neoplasia intraepitelial prostática y cáncer de próstata (Rebello y et al, 2021).

De manera interesante, hay varias investigaciones que muestran la existencia de relaciones directas o indirectas entre la microbiota y el cáncer de próstata. Diversos grupos han señalado que especies como Streptococcus, Bacteroides massiliensis, Faecalibacterium prausnitzii, Eubacterium rectale y Mycoplasma genitalium están asociadas con diferentes riesgos de desarrollo de cáncer de próstata o extensión de la enfermedad del cáncer de próstata (Sha y et al, 2019, Shiao y et al, 2016; Shrestha y et al, 2018). También se ha reportado que los cambios en la composición de la microbiota inducidos por el uso de antibióticos tales como penicilinas, quinolonas, sulfonamidas y tetraciclinas modifican la permeabilidad intestinal y alteran el metabolismo de ciertos compuestos tales como el calcio presente en los productos lácteos, la carne roja o su grasa, alimentos que pueden estar asociados con un mayor riesgo de patologías de próstata y que en consecuencia incrementan el riesgo de desarrollar cáncer de próstata (de la Garza y et al, 2014, Liss y et al, 2018; Sha et al,. 2019). Otro estudio, realizado in vivo en roedores mostró que la infección bacteriana con Helicobacter hepaticus del tracto gastrointestinal potencia la neoplasia intraepitelial de próstata (Poutahidis y et al, 2013). De igual manera, se ha mostrado que Clostridium scindens convierte los glucocorticoides en el intestino en andrógenos mediante la escisión de la cadena lateral, lo que podría contribuir al desarrollo del cáncer de próstata en aquellos casos en los cuales el AR se encuentra funcionalmente hiperactivo en la glándula prostática (Ridlon y et al, 2013; Rebello y et al, 2021). Con relación a la bacteria Escherichia coli, común en el intestino humano y que típicamente está en simbiosis con el hospedero, se ha reportado que puede inducir una respuesta genotóxica de daño al ADN con signos de reparación incompleta cuando se realiza una infección in vivo con esta bacteria (Cuevas-Ramos y et al, 2010), además de que se ha asociado con la inflamación de la próstata, lo cual toma relevancia ya que varios estudios han mostrado que hay un aumento en el riesgo de cáncer de próstata en hombres con prostatitis o hipertrofia prostática benigna en su historial (Elkahwaji y et al, 2005; Katongole y et al, 2020; Sha y et al, 2020). También se ha reportado que la presencia de Mycoplasma genitalium ha sido asociada a enfermedades que inducen inflamación como prostatitis crónica y uretritis, esta inflamación puede derivar en cambios neoplásicos en la próstata (Amirian y et al, 2013). Asimismo, se ha planteado la hipótesis de que las especies reactivas de oxígeno (radical superóxido y peróxido de hidrógeno) y las especies reactivas de nitrógeno (óxido nítrico y peroxinitrito) se liberan a través de las células inmunitarias durante los momentos de inflamación, dañando directamente las células y el ADN. Este daño oxidativo y muerte celular es la causa de la atrofia inflamatoria proliferativa, que se identifica como un precursor de la neoplasia prostática (Sha y et al, 2020). Aunque los receptores tipo Toll (Toll-like receptors, TLRs) ejercen vigilancia inmunológica e inducen muerte celular inmunomediada para eliminar las células tumorales, la inflamación crónica mediada por DAMPs puede promover la iniciación de tumores (Dutta y Lim, 2020, Fuentes., 2017). Finalmente, hay varios estudios que sugieren la presencia in situ de microorganismos en el tejido prostático canceroso; donde se ha reportado la presencia de 83 especies bacterianas, entre las que se identificaron Cutibacterium acnes spp, Acinetobacter spp, Escherichia spp, Pseudomonas spp, Methylophilus spp y Streptococcus spp en biopsias de pacientes a los cuales se les realizó una prostatectomía radical (Cohen y et al, 2005; Sfanos y et al, 2008; Yow y et al, 2017). 


\section{Prevención y tratamiento del cáncer de próstata}

Como en todo tipo de cáncer, un diagnóstico oportuno puede marcar la diferencia en el grado de desarrollo de la enfermedad; para el caso particular del cáncer de próstata la Asociación Española Contra el Cáncer (AECC) recomienda que los hombres de 50 años o más deben someterse a los métodos de detección específicos; los cuales consisten en la medición en sangre de los niveles de antígeno prostático específico (APE), una glicoproteína altamente inmunógena que se produce de manera exclusiva en la glándula prostática, y en la exploración física de la glándula prostática mediante tacto rectal; ambas metodologías son complementarias y en conjunto proporcionan un mejor índice de detección. La frecuencia con la que se deberá realizar estos exámenes dependerá de los niveles de APE muestreados en cada individuo. Una prueba adicional de utilidad es la de fosfatasa ácida (PAS), que se utiliza para vigilar las concentraciones en sujetos diagnosticados con cáncer prostático y que están bajo tratamiento (De la Garza y Juárez-Sánchez, 2014). Con relación a la prevención, un estudio reveló que altas cantidades de folato están asociadas a la disminución de incidencia de cáncer de próstata por lo que se ha exhortado a los hombres a usar probióticos que ayuden a la producción natural de folato, sin embargo, se necesita realizar más estudios para comprobar la eficacia de éste (Sha y et al, 2020). La prognosis de un individuo con cáncer de próstata es muy variable y dependiente del momento en que sea detectado por primera vez; si el cáncer se encuentra confinado únicamente a la próstata y es inmediatamente tratado, la esperanza de vida a diez años puede llegar a un $99 \%$. Sin embargo, si el cáncer se ha convertido en metastásico la esperanza de vida se reduce a un $30 \%$ en cinco años (Rebello y et al, 2021), de aquí la importancia de desarrollar terapias que sean más efectivas y con menores efectos secundarios para la eliminación definitiva de este padecimiento. En este sentido, el tratamiento del cáncer ha experimentado un gran avance en los últimos años con el mejoramiento de la quimioterapia, radioterapia y la inmunoterapia hacia tratamientos multimodales y personalizados (Sha y et al, 2019; Katongole y et al, 2020). En los apartados siguientes describiremos brevemente cada una de ellas además de su relación con la microbiota, y de igual manera, terapias basadas en la modulación de esta última para el tratamiento de los distintos tipos de cáncer, incluido el de próstata.

\section{Quimioterapia}

La quimioterapia es el uso de fármacos para tratar el cáncer con el objetivo de detener directamente o ralentizar el crecimiento celular del tumor dejando a las células cancerosas incapaces de duplicarse o iniciando artificialmente el proceso normal de muerte celular (apoptosis). Es importante recalcar que los fármacos quimioterapéuticos se utilizan para alterar el comportamiento de las células tumorales, pero también pueden dañar a células sanas de tasa de proliferación alta, como las células que revisten la cavidad oral y los intestinos.

La quimioterapia se puede administrar en muchas formas (intramuscular, intravenosa, tópica u oral) y los medicamentos de quimioterapia atacan a las células en diferentes fases del ciclo celular; de estos, existen distintos tipos, los cuales se describirán a continuación. 
Los agentes alquilantes (altretamina, cisplatino, ifosfamida, tiotepa, ciclofosfamida, etc), impiden la división de las células al formar enlaces cruzados con el ADN, impidiendo su replicación. Los antimetabolitos (azacitidina, clofarabina, metotrexato, tioguanina, etc) interfieren con el ADN y el ARN, sustituyendo las bases nitrogenadas necesarias para formar estas moléculas y cuando esto sucede, el ADN no se puede replicar, y la célula no puede entrar en división. Los antibióticos antitumorales, son medicamentos diferentes a los antibióticos que se usan para tratar infecciones ya que ejercen su acción al cambiar el ADN dentro de las células cancerosas para impedir que crezcan y se multipliquen; por ejemplo, las antraciclinas son antibióticos que interfieren con las enzimas involucradas en la replicación de ADN durante el ciclo celular, estos se ligan con el ADN de modo que este no pueda hacer copias de sí mismo y una célula no pueda reproducirse. Los inhibidores de la topoisomerasa (Irinotecan, irinotecan liposomal, topotecan), también llamados alcaloides de origen vegetal, interfieren con las enzimas topoisomerasas, que ayudan a separar las hebras de ADN para que se puedan copiar. Los inhibidores de la mitosis (taxanos y alcaloides), son compuestos derivados de productos naturales, como las plantas que ejercen su acción al detener la división celular para la formación de nuevas células, pero pueden dañar las células en todas las fases al evitar que las enzimas sinteticen las proteínas necesarias para la reproducción de las células (ACS, 2019; Cheung-Ong y et al, 2013; Hosoya y Miyagawa, 2014).

Debido al tratamiento, es probable que la quimioterapia induzca una disbiosis y que ésta a su vez incremente la toxicidad y disminuya la efectividad del fármaco; esta situación puede ser ocasionada por diversos factores conocidos en conjunto como "TIMER”, que significa Translocación, Inmunomodulación, Metabolismo, degradación Enzimática y diversidad Reducida (Alexander y et al, 2017). Por ejemplo, la translocación resultado de la disbiosis inducida por ciclofosfamida puede desencadenar un proceso inflamatorio debido a la movilización de células del sistema inmune, por lo cual altera la permeabilidad de la barrera intestinal y permite una migración de microorganismos relativamente inocuos (como las especies Lactobacillus johnsonii y Enterococcus hirae) a otros órganos, entre ellos ganglios linfáticos, tonsilas o el bazo, donde pueden estimular las respuestas inmunitarias antitumorales, aunque también puede haber migración de microorganismos que causen alteraciones nocivas al organismo (Viaud y et al, 2013). Se ha mostrado que algunas cepas presentes en la microbiota tienen la capacidad de facilitar la inmunomodulación para algunos de los fármacos quimioterapéuticos (Iida y et al, 2013), por ejemplo, Barnesiella intestinihominis puede incrementar el número de linfocitos $\mathrm{T} \mathrm{CD} 8^{+}$citotóxicos y $\mathrm{T}_{\mathrm{H}} 1$ así como de la producción de interferón g (Daillère y et al, 2016). En el caso del metabolismo y la degradación enzimática, las bacterias del tubo digestivo participan en procesos metabólicos como la reducción, hidrólisis, dihidroxilación y desalquilación, que podrían ser consideradas al pensar en quimioterapéuticos. Finalmente, para una diversidad reducida, la quimioterapia puede provocar cambios en la microbiota que pueden conducir a resultados adversos como mucositis, colitis o diarrea severa por proliferación de patógenos (Alexander y et al, 2017; Sha y et al, 2020).

\section{Radioterapia}

La radioterapia es un tratamiento contra el cáncer que usa altas dosis de radiación de partículas u ondas de alta energía, tales como los rayos $\mathrm{X}$, rayos gamma, rayos de electrones o de protones, para destruir células cancerosas y reducir tumores sólidos. La radiación actúa sobre el ADN que se encuentra dentro 
de las células produciendo pequeñas roturas; éstas evitan que las células cancerosas crezcan y se dividan provocándoles la muerte (ACS, 2019). La dosis de radiación se mide en Gray (Gy); cuando la radioterapia se administra sola, el esquema más comúnmente usado es 2 Gy en una única fracción por día, cinco días a la semana, durante siete semanas. Sin embargo, se han evaluado los regímenes alternativos de radioterapia para reducir el tiempo total de tratamiento (Baujat y et al, 2010). Aproximadamente, seis de cada diez personas con enfermedades tumorales reciben radioterapia en algún momento de la evolución de la enfermedad, como parte importante de su tratamiento oncológico, bien como terapia exclusiva o asociada a otras modalidades (Delaney y et al, 2005; Jaffray, 2012). El tratamiento con radioterapia siempre es individualizado, es decir, cada enfermo tendrá su tratamiento específico distinto al de otro. Esto, debido a que es un tratamiento que presenta una gran heterogeneidad en cuanto a las respuestas de los pacientes (Begg y et al, 2011), tanto por factores clínicos (tamaño del tumor, estadío de la enfermedad), como biológicos (radioresistencia intrínseca, hipoxia, infiltración de células proinflamatorias, cambios en la inmunidad del hospedero).

La radioterapia ocasiona efectos secundarios nocivos que incluso pueden llegar a impedir que el tratamiento se lleve a cabo en su totalidad, se ha reportado que puede ocasionar mucositis gastrointestinal, dermatitis, cistitis y aplasia medular; esto dependiendo de factores de riesgo inherentes al paciente tales como edad, sexo, comorbilidades, adicciones y carga genética, entre otros (Bentzen y Overgaard, 1994). La radioterapia también puede inducir disbiosis, modificando las proporciones relativas de las distintas cepas presentes en el intestino. Se ha reportado que la radiación incrementa la población de los filos de Bacteroidetes, y Proteobacteria y reduce la de los filos Actinobacteria y Deferribacteres (Touchefeu y et al, 2014; Kim et al 2015, Mitra y et al, 2020); el filo Firmicutes muestra una respuesta dual, incrementándose algunos géneros (Roseburia, Dialister, Veillonella) y reduciéndose otros (Clostridium. Faecalibacterium, Oscillibacter) (Wang y et al, 2015, Dutta y Lim, 2020). El cambio de la microbiota en pacientes irradiados ha sido relacionado estrechamente con la presencia de diarrea severa y fatiga (Al-Qadami y et al, 2015). La disbiosis ocasionada por irradiación local de la pelvis daña la mucosa y el epitelio intestinal, comprometiendo la integridad de esta barrera e induce la respuesta inmune con la subsecuente producción de especies reactivas de oxígeno (radical superóxido y peróxido de hidrógeno) (van Vliet y et al, 2010). Finalmente, se ha reportado que la radioterapia induce en algunos pacientes el incremento de Clostridium difficile, cepa que está relacionada con tasas altas de mortalidad (Neemann y Freifeld, 2017).

\section{Inmunoterapia}

Como parte de su función normal, el sistema inmune detecta y destruye las células anormales además de que impide o frena el crecimiento de muchos tipos de cáncer. La inmunoterapia es un tipo de tratamiento que estimula las defensas naturales del organismo para combatir diversos padecimientos; dicha terapia utiliza sustancias producidas por el cuerpo o de diseño para mejorar o restaurar la función del sistema inmunitario y en los últimos años se han estudiado diversos compuestos para su aplicación inmunomoduladora en cáncer (Chen y et al, 2019; Ma y et al, 2021, Qiu y et al, 2021). Durante el desarrollo de la enfermedad a menudo las células cancerosas crean un microambiente inmunosupresor para mediar en el "escape" inmunológico del tumor (conocido como microambiente tumoral). Este mecanismo de es- 
cape inmunológico puede revertirse mediante los inhibidores del punto de control inmunitario (immune checkpoint inhibitors, ICI), los cuales bloquean los receptores inhibitorios expresados en los linfocitos $\mathrm{T}$, como el antígeno 4 del linfocito $\mathrm{T}$ citotóxico (CTLA-4), la proteína de muerte celular programada 1 (PD-1) o su ligando, el ligando de muerte celular programada 1 (PD-L1), que impiden la activación de la respuesta inmunológica del hospedero (Lyon y et al, 2018; Williamson y et al, 2021). De igual manera, se ha mostrado la utilidad de la terapia con anticuerpos anti CD47, molécula que participa en el escape inmunológico del tumor (Liu y et al, 2015). Sin embargo, se ha reportado que algunos pacientes presentan resistencia innata o adquirida a los ICI, lo cual dificulta su aplicación como terapia. En este sentido, la microbiota intestinal ha sido relacionada con la resistencia o permisividad de estos tratamientos, debido a sus efectos moduladores de la respuesta neuroinmunoendocrina del hospedero, por lo que se ha intentado caracterizar las distintas cepas que se encuentran involucradas en dichas respuestas (Sivan y et al, 2015; Vètizou y et al, 2015). En este sentido, se ha mostrado que las cepas Bifidobacterium pseudolongum, Lactobacillus johnsonii, y Olsenella pueden potenciar la eficiencia de inmunoterapia anti-CTLA-4 y anti PD-L1 (Mager y et al, 2020).

Dado que los microorganismos intestinales influyen en la reacción inmunitaria antitumoral local y sistémica modulada por la interacción de PRR con sus PAMP y DAMP, la disbiosis intestinal puede afectar el resultado del tratamiento. Se ha observado que antibióticos de amplio espectro suministrados antes, durante o después del tratamiento con ICI alteran el microbioma intestinal y dan como resultado una tasa de respuesta antitumoral más baja. Las respuestas deficientes al tratamiento antitumoral se asociaron con una disminución de Bacteroides thetaiotaomicron, Bacteroides uniformis y Burkholderia cepacia, y un aumento de Clostridium; dicha disbiosis también se asoció con daño de las mucosas y colitis. (Dutta y Lim, 2020). Varios estudios han demostrado cómo las actividades específicas de la microbiota podrían afectar positivamente la eficacia de la ICI en pacientes inmunocomprometidos. En este sentido, un estudio de 2015 de Vétizou et al reveló que en presencia de Bacteroides thetaiotaomicron y Bacteroides fragilis, ciertos anticuerpos tienen una capacidad mejorada de unión y bloqueo en ratones con tumores tratados con antibióticos. Este efecto se atribuyó al aumento de las actividades de respuesta inmune Th1, y la promoción de la maduración de las células dendríticas intratumor. En un entorno más clínico, se demostró que el tratamiento a pacientes con cáncer con anti-PD1 inducía el enriquecimiento con el género Faecalibacterium, la familia Ruminococcus y la orden Clostridiales y esto a su vez incrementaba el número de linfocitos $\mathrm{T} \mathrm{CD}^{+} \mathrm{y} \mathrm{CD}^{+}$, resultando en un incremento en la inmunidad sistémica y antitumoral (Gopalakrishnan y et al, 2018; Suraya y et al, 2020).

\section{Efecto e influencia de la modulación del microbioma en el tratamiento del cán- cer}

Uno de los factores principales para que resulte exitoso el manejo terapéutico en la eliminación del cáncer de un organismo es que su sistema inmune se encuentre en estado óptimo, y como lo hemos descrito en las secciones anteriores, en esto influye el estado de la microbiota intestinal. Tratamientos farmacológicos agresivos -directos o indirectos- contra la microbiota, como el uso de antibióticos de amplio espectro pueden ocasionar disbiosis, la cual puede derivar en resultados negativos, como mala respuesta al tratamiento e inducción de toxicidad (Ahmed y et al, 2018). Otros fármacos 
con potencial efecto nocivo sobre la homeostasis de la microbiota serían los analgésicos opioides, ya que estos alteran la motilidad intestinal y promueven la proliferación bacteriana de cepas potencialmente nocivas, como Clostridium difficile (Dutta y Lim, 2020).

Una clara lección de los estudios anteriores es que la modulación del microbioma puede influir sobre la efectividad de las distintas terapias aplicadas actualmente. Es por esto que desde la década pasada se han realizado estudios tanto básicos como clínicos con el uso de prebióticos, probióticos y/o sinbióticos (combinaciones sinérgicas de prebióticos y probióticos) como auxiliares no solo de las terapias contra el cáncer, sino también de la salud durante el proceso de envejecimiento (Ale y Binetti, 2021). En este sentido, estudios en humanos mayores de cincuenta años suplementados con el prebiótico galactooligosacárido mostraron que hay un incremento en la población intestinal del género Bifidobacterium (Walton y et al, 2012). A su vez, la aplicación de un compuesto sinbiótico de Bifidobacteria e inulina incrementó las poblaciones de los filos Actinobacteria y Firmicutes (Macfarlane y et al, 2013). Por otro lado, se ha demostrado que los probióticos inciden positivamente sobre diversas afecciones patológicas relacionadas con el cáncer y/o modalidades convencionales de dichas terapias. Uno de esos cambios, es la disminución de alteraciones gastrointestinales que incluyen náuseas, vómitos, diarrea y/o estreñimiento, en la que el cambio de la población de la microbiota ha demostrado su éxito. Otro estudio en pacientes canadienses observó el efecto de la aplicación de probióticos en pacientes con cáncer pélvico sometidos a radioterapia, en los que la diarrea inducida por radiación es una reacción secundaria común. Sorprendentemente, en estos pacientes tratados con los probióticos pudieron reducir su incidencia sin efectos secundarios aparentes (Demers y et al, 2013). En esta misma dirección, se ha mostrado que la administración de probióticos después de la terapia contra el cáncer alivia el estrés relacionado con el tubo digestivo y promueve el repoblamiento de la microbiota, como en el caso de Lactobacillus rhamnosus que se administra a menudo como complemento del tratamiento tradicional del cáncer colorrectal para promover la simbiosis de la microbiota gastrointestinal ya que promueve una respuesta antiinflamatoria y da lugar a una mayor regresión tumoral en modelos animales (Sha y et al, 2020).

\section{Terapias coadyuvantes con microbiota potenciales para el manejo del cáncer.}

Las siguientes terapias se basan en la estrecha relación que existe entre la microbiota y el cáncer, aún están en desarrollo y están mayormente inmiscuidas en el tratamiento de cáncer del tracto gastrointestinal (Figura 3). No obstante, es posible diseñar terapias específicas para su uso en ciertos tipos de cáncer, incluido el de próstata. 
Figura 3

Representación esquemática de tres enfoques para manipular la microbiota intestinal y la barrera intestinal para mejorar los resultados terapéuticos del cáncer, y su influencia sobre la homeostasis intestinal.

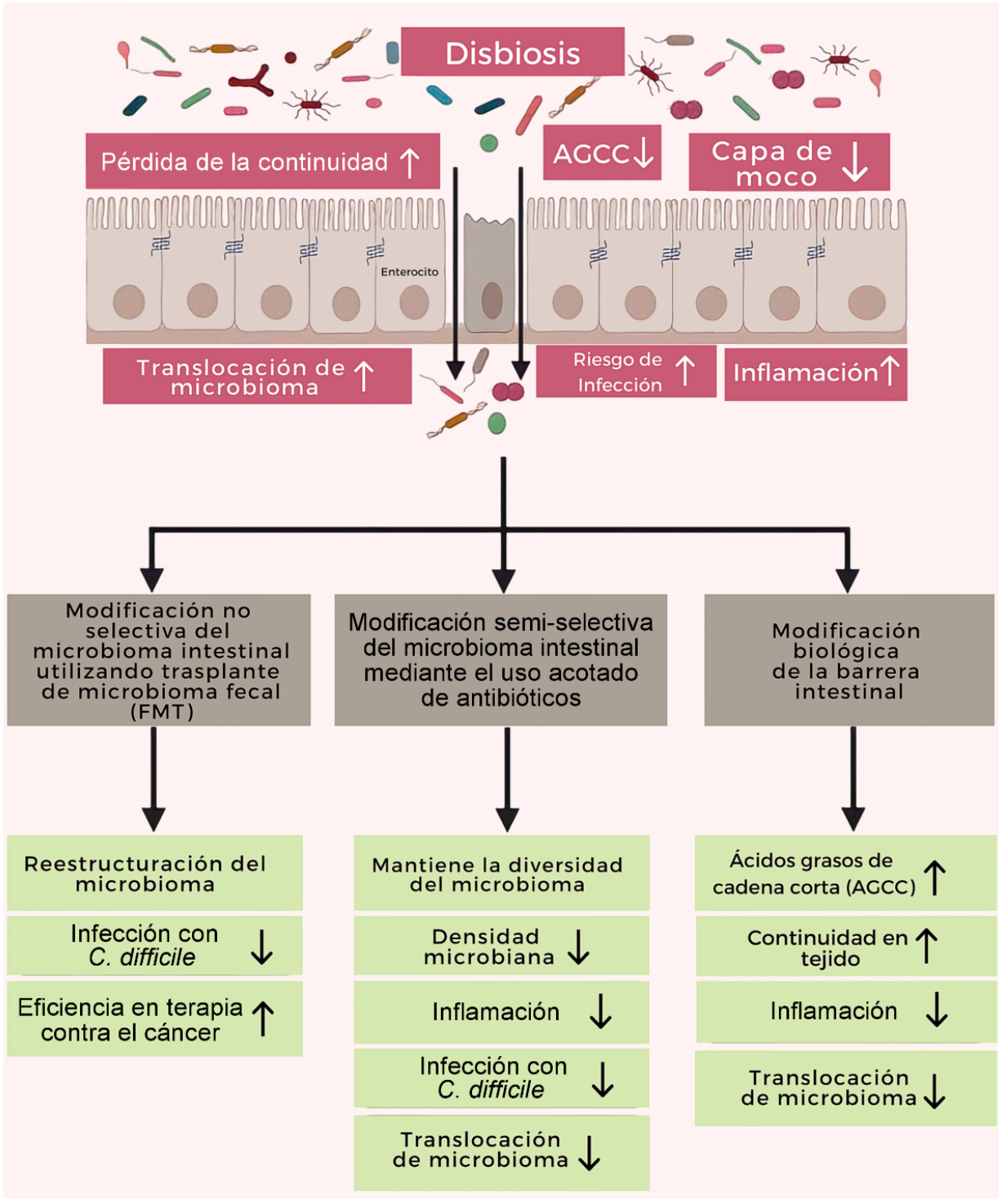

Adaptado de Dutta, D., Lim, S.H. (2020). 
Flores-Martínez, L. P.; G-Santoyo, I.; Arriaga-Canon, C.; Jiménez-Trejo, F. J.; Tapia Rodríguez, M.

\section{a. Modificación no selectiva de la microbiota intestinal, utilizando trasplante de microbiota fecal (FMT).}

En teoría, la modificación de la microbiota intestinal se logra mejor mediante FMT, ya que este no sólo repondrá la microbiota intestinal disbiótica con los microbios deficientes, sino que también permitirá el restablecimiento de una comunidad microbiana finamente equilibrada e incluso podrá restablecer/reparar la barrera intestinal (Kassam y et al, 2013; de Castro y et al, 2014; Cheng y et al, 2019). Sin embargo, la alta variabilidad individual y una caracterización limitada de la composición del microbioma dificulta su aplicación en muchos casos. Evidentemente, el avance en la caracterización individual de los microbiomas y mejoras en los sistemas de cultivo de organismos anaerobios o mixtos favorecerán el desarrollo de una terapia personalizada con una mejor respuesta.

\section{b. Modificación semi-selectiva de la microbiota intestinal y uso restringido de antibióticos.}

La asociación entre el desarrollo de una infección por Clostridium difficile (CDI), enterococos resistentes a la vancomicina (VRE) y el uso de antibióticos también sugiere la necesidad de evitar el uso rutinario de este tratamiento como profilácticos en pacientes. La profilaxis con rifaximina, un antibiótico de absorción mínima, puede ser la respuesta. La rifaximina se asoció con una alteración menor de la diversidad microbiana intestinal, en comparación con otros antibióticos. Otros efectos beneficiosos de la rifaximina incluyen protección contra enteroinfecciones, especialmente CDI, y restauración de la barrera de la mucosa intestinal (Bajaj y et al, 2018; Dutta y et al, 2020). En este sentido, la búsqueda de fármacos tanto específicos como de mediano espectro ayudará a modular las poblaciones de una mejor manera, con resultados que inhiban la presencia de disbiosis y otros efectos colaterales no deseados.

\section{c. Modificación biológica de la barrera intestinal con prebióticos, probióticos y sinbióticos.}

Como ya se describió previamente, se han utilizado algunos prebióticos, probióticos y sinbióticos para promover la proliferación de microbios intestinales involucrados en la producción de ácidos grasos de cadena corta. Sin embargo, debido a la variabilidad en el contenido de estos compuestos, las poblaciones resultantes en el intestino no se pueden predecir de manera consistente. Para una mejor terapia con estos compuestos, se requiere un mayor conocimiento de las distintas poblaciones de cada individuo para poder reponer o enriquecer su microbiota intestinal con microorganismos adecuados para la recuperación de la homeostasis intestinal.

En suma, la implementación de todas estas opciones terapéuticas es con el fin de evitar o eliminar la pérdida de la continuidad de la barrera de la mucosa gastrointestinal, lo cual a su vez evitará la migración bacteriana a otros órganos disminuyendo la incidencia de cáncer y evitando la desregulación de la respuesta inmune sistémica y antitumoral (Dao y et al, 2016; Dutta y Lim, 2020; Qiu y et al, 2021).

Es interesante notar que la mayoría, si no todas, de las opciones de tratamiento que se han explorado en el campo de la microbiota se modulan principalmente a nivel intestinal. Esto, se debe principalmente a su función como regulador central para las poblaciones locales modulando la respuesta inmune sistémica y la expresión génica celular. Aunque las metodologías actuales han tenido un avance importante en los 
últimos años, aún no son capaces de brindarnos una mejor caracterización de los hologenomas individuales, conocimiento necesario y de particular importancia dada la alta heterogeneidad presente entre los seres humanos (Aarnoutse y et al, 2019; Sánchez-Quinto y et al, 2020; Suraya y et al, 2020).

\section{Perspectivas}

El papel de la microbiota intestinal y su relación tan estrecha con el sistema inmune y por ende con los procesos carcinogénicos brindan una oportunidad sin precedentes para explorar nuevas aplicaciones diagnósticas y terapéuticas para los diversos tipos de cáncer existentes. El conjunto de estudios realizados en los últimos tiempos nos han mostrado que existe una gran variabilidad individual en los seres humanos y al mismo tiempo sugieren que se requiere una caracterización más profunda de los elementos que conforman al hologenoma. Sin duda, una de las limitantes metodológicas importantes para esta caracterización, es el hecho de que varias de las especies de microorganismos que lo conforman son anaerobias, por lo que el desarrollo de técnicas de cultivo adecuadas resultará de gran ayuda para identificar de manera más específica a los componentes de cada hologenoma. De igual manera, el avance técnico nos permitirá realizar una mejor caracterización de los microbiomas presentes en la mayoría de los órganos descritos e incluso permitirá la detección de microorganismos en órganos y tejidos aún no caracterizados. Esto redundará en la aplicación de terapias altamente personalizadas, en donde se podrá realizar la caracterización completa del hologenoma del paciente y con ese conocimiento se podrá realizar el ajuste de sus poblaciones de microorganismos in situ para un efecto local y una modulación tanto de la respuesta inmune como de las terapias antitumorales que permita erradicar el cáncer y disminuir al mínimo los efectos secundarios adversos. Para el caso particular de pacientes con predisposición a presentar cáncer de próstata, una mejor caracterización de las especies de microorganismos que colonizan la glándula prostática durante los eventos de prostatitis o hipertrofia prostática benigna permitirán el desarrollo de tratamientos personalizados y con alta especificidad cuya aplicación contribuirá a disminuir el aporte de la microbiota nociva a la inflamación de la glándula prostática, minimizando la afectación al resto del holobioma y disminuyendo la aparición de lesiones tumorales en la próstata y en consecuencia la generación de un cáncer metastásico.

\section{Conclusiones}

Aunque claramente se ha avanzado mucho en los últimos años sobre el conocimiento del papel del hologenoma ya sea en la etiología o sobre los distintos tratamientos contra el cáncer, es evidente que aún falta por descubrir bastante información sobre él. Diversos estudios actuales han mostrado que la modulación de la microbiota intestinal y su efecto sobre la etiología y las terapias contra el cáncer tales como la radioterapia, quimioterapia e inmunoterapia da buenos resultados. Sin embargo, no podemos ignorar que al mismo tiempo nos muestran el efecto de la gran heterogeneidad del hologenoma, la cual puede incrementar o disminuir la efectividad de dichas terapias dependiendo de la composición de cada individuo. Por esta razón, existe una gran necesidad de incrementar los estudios enfocados en esta área, que contribuyan a la comprensión de la composición microbiana, su papel en la inmunomodulación, así como de los mecanismos específicos con los que el hologenoma participa tanto en la patogénesis como en las distintas terapias contra el cáncer. Sin duda, veremos avances en este sentido en los próximos años. 
Flores-Martínez, L. P.; G-Santoyo, I.; Arriaga-Canon, C.; Jiménez-Trejo, F. J.; Tapia Rodríguez, M.

\section{Referencias}

Aarnoutse, R., Ziemons, J., Penders, J., Rensen, S.S., de Vos-Geelen, J., Smidt, M.L. (2019). The Clinical Link between Human Intestinal Microbiota and Systemic Cancer Therapy. Int. J. Mol. Sci. 20(17) 4145. https://doi.org/10.3390/ijms20174145

ACS. Redactores y equipo de editores médicos de la Sociedad Americana Contra El Cáncer. (2019). Cómo funcionan los medicamentos de quimioterapia. American Cancer Society. Cancer.org | 1.800.227.2345. https:/www.cancer.org/content/dam/CRC/PDF/Public/8461.96.pdf

Ahmed, J., Kumar, A., Parikh, K., Anwar, A., Knoll, B. M., Puccio, C., Chun, H., Fanucchi, M., Lim, S. H. (2018). Use of broad-spectrum antibiotics impacts outcome in patients treated with immune checkpoint inhibitors. Oncoimmunology, 7(11), e1507670. https://doi.org/10.1080/2162402X.2018.1507670

Al-Qadami, G., Van Sebille, Y., Le, H., \& Bowen, J. (2019). Gut microbiota: implications for radiotherapy response and radiotherapy-induced mucositis. Expert Rev. Gastroenterol Hepatol. 13(5), 485-496. https://doi.org/10.1080/17474124.2019.1595586

Ale, E. C., Binetti, A. G. (2021). Role of Probiotics, Prebiotics, and Synbiotics in the Elderly: Insights Into Their Applications. Front Microbiol. 12, 631254. https://doi.org/10.3389/fmicb.2021.631254

Alexander, J. L., Wilson, I. D., Teare, J., Marchesi, J. R., Nicholson, J. K., Kinross, J. M. (2017). Gut microbiota modulation of chemotherapy efficacy and toxicity. Nat. Rev. Gastroenterol. Hepatol. 14(6), 356-365. https://doi.org/10.1038/nrgastro.2017.20

Amirian, E.S., Petrosino, J.F., Ajami, N.J., Liu, Y., Mims, M.P., Scheurer, M.E. (2013). Potential role of gastrointestinal microbiota composition in prostate cancer risk. Infect Agents Cancer 8, 42. https://doi.org/10.1186/1750-9378-8-42

Bajaj, J. S., Barbara, G., DuPont, H. L., Mearin, F., Gasbarrini, A., Tack, J. (2018). New concepts on intestinal microbiota and the role of the non-absorbable antibiotics with special reference to rifaximin in digestive diseases. Dig. Liver Dis. 50(8), 741-749. https://doi.org/10.1016/j.dld.2018.04.020

Baujat, B., Bourhis, J., Blanchard, P., Overgaard, J., Ang, K. K., Saunders, M., Le Maître, A., Bernier, J., Horiot, J. C., Maillard, E., Pajak, T. F., Poulsen, M. G., Bourredjem, A., O’Sullivan, B., Dobrowsky, W., Andrzej, H., Skladowski, K., Hay, J. H., Pinto, L. H., Fu, K. K., .. MARCH Collaborative Group (2010). Hyperfractionated or accelerated radiotherapy for head and neck cancer. The Cochrane Database Syst Rev, (12), CD002026. https://doi.org/10.1002/14651858.CD002026

Begg, A. C., Stewart, F. A., Vens, C. (2011). Strategies to improve radiotherapy with targeted drugs. Nat. Rev. Cancer 11 (4), 239-253. https://doi.org/10.1038/nrc3007

Bentzen, S. M., Overgaard, J. (1994). Patient-to-Patient Variability in the Expression of Radiation-Induced Normal Tissue Injury. Semin. Radiat. Oncol. 4(2), 68-80. https://doi.org/10.1053/SRAO00400068

Bhatt, A.P., Redinbo, M.R., Bultman, S.J. (2017). The role of the microbiome in cancer development and therapy. CA Cancer J Clin 67: 326-344. https://doi.org/10.3322/caac.21398

Brown, E. M., Kenny, D. J., Xavier, R. J. (2019). Gut Microbiota Regulation of T Cells During Inflammation and Autoimmunity. Annu Rev Immunol, 37, 599-624. https://doi.org/10.1146/annurev-immunol-042718-041841 
Chen, D., Wu, J., Jin, D. (2019). Fecal microbiota transplantation in cancer management: Current status and perspectives. Int. J. Cancer 145, 2021-203. https://doi.org/10.1002/ijc.32003

Cheng, Y. W., Phelps, E., Ganapini, V., Khan, N., Ouyang, F., Xu, H., Khanna, S., Tariq, R., Friedman-Moraco, R. J., Woodworth, M. H., Dhere, T., Kraft, C. S., Kao, D., Smith, J., Le, L., El-Nachef, N., Kaur, N., Kowsika, S., Ehrlich, A., Smith, M., ... Fischer, M. (2019). Fecal microbiota transplantation for the treatment of recurrent and severe Clostridium difficile infection in solid organ transplant recipients: A multicenter experience. Am. J Transplant. 19(2), 501-511. https://doi.org/10.1111/ajt.15058

Cheung-Ong, K., Giaever, G., Nislow, C. (2013). DNA-damaging agents in cancer chemotherapy: serendipity and chemical biology. Chem Biol. 20(5):648-659. https://doi.org/10.1016/j.chembiol.2013.04.007

Cohen, R. J., Shannon, B. A., McNeal, J. E., Shannon, T., Garrett, K. L. (2005). Propionibacterium acnes associated with inflammation in radical prostatectomy specimens: a possible link to cancer evolution? J. Urol. 173(6), 1969-1974. https://doi.org/10.1097/01.ju.0000158161.15277.78

Cuevas-Ramos, G., Petit, C. R., Marcq, I., Boury, M., Oswald, E., Nougayrède, J. P. (2010). Escherichia coli induces DNA damage in vivo and triggers genomic instability in mammalian cells. Proc. Natl. Acad. Sci. US A, 107(25), 11537-11542. https://doi.org/10.1073/pnas.1001261107

Daillère, R., Vétizou, M., Waldschmitt, N., Yamazaki, T., Isnard, C., Poirier-Colame, V., Duong, C., Flament, C., Lepage, P., Roberti, M. P., Routy, B., Jacquelot, N., Apetoh, L., Becharef, S., Rusakiewicz, S., Langella, P., Sokol, H., Kroemer, G., Enot, D., Roux, A., ... Zitvogel, L. (2016). Enterococcus hirae and Barnesiella intestinihominis Facilitate Cyclophosphamide-Induced Therapeutic Immunomodulatory Effects. Immunity 45(4), 931-943. https://doi.org/10.1016/j.immuni.2016.09.009

Dao, M. C., Everard, A., Aron-Wisnewsky, J., Sokolovska, N., Prifti, E., Verger, E. O., Kayser, B. D., Levenez, F., Chilloux, J., Hoyles, L., MICRO-Obes Consortium, Dumas, M. E., Rizkalla, S. W., Doré, J., Cani, P. D., \& Clément, K. (2016). Akkermansia muciniphila and improved metabolic health during a dietary intervention in obesity: relationship with gut microbiome richness and ecology. Gut, 65(3), 426-436. https://doi.org/10.1136/gutjnl-2014-308778

Davenport, E.R., Sanders, J.G., Song, S.J., Amato, K.R., Clark, A.G., Knight, R. (2017). The human microbiome in evolution. BMC Biol. 15 (127): 1-12. https://doi.org/10.1186/s12915-017-0454-7

de Castro, C. G., Jr, Ganc, A. J., Ganc, R. L., Petrolli, M. S., Hamerschlack, N. (2015). Fecal microbiota transplant after hematopoietic SCT: report of a successful case. Bone Marrow Transplant. 50(1), 145. https://doi.org/10.1038/bmt.2014.212

de la Garza Salazar, J.G., Juárez Sánchez, P. (2014). El cáncer. UANL, La ciencia a tu alcance 1, 17-18, 72. http://eprints.uanl.mx/3465/1/El_Cancer.pdf

Delaney, G., Jacob, S., Featherstone, C., Barton, M. (2005). The role of radiotherapy in cancer treatment: estimating optimal utilization from a review of evidence-based clinical guidelines. Cancer, 104(6), 1129-1137. https://doi.org/10.1002/cncr.21324

Demers, M., Dagnault, A., Desjardins, J. (2014). A randomized double-blind controlled trial: impact of probiotics on diarrhea in patients treated with pelvic radiation. Clin. Nutr. 33(5), 761-767. https://doi.org/10.1016/j.clnu.2013.10.015 
Flores-Martínez, L. P.; G-Santoyo, I. ; Arriaga-Canon, C.; Jiménez-Trejo, F. J.; Tapia Rodríguez, M.

Dutta, D., Li, K., Methe, B., \& Lim, S. H. (2020). Rifaximin on intestinally-related pathologic changes in sickle cell disease. Am. J. Hematol. https://doi.org/10.1002/ajh.25722

Dutta, D., Lim, SH. (2020). Bidirectional interaction between intestinal microbiome and cancer: opportunities for therapeutic interventions. Biomark Res, 8(31). https://doi.org/10.1186/s40364-020-00211-6

Elkahwaji, J. E., Hauke, R. J., \& Brawner, C. M. (2009). Chronic bacterial inflammation induces prostatic intraepithelial neoplasia in mouse prostate. Br. J. Cancer, 101(10), 1740-1748. https://doi. org/10.1038/sj.bjc. 6605370

Falony, G., Joossens, M., Vieira-Silva, S., Wang, J., Darzi, Y., Faust, K., Kurilshikov, A., Bonder, M. J., Valles-Colomer, M., Vandeputte, D., Tito, R. Y., Chaffron, S., Rymenans, L., Verspecht, C., De Sutter, L., Lima-Mendez, G., D’hoe, K., Jonckheere, K., Homola, D., Garcia, R., ... Raes, J. (2016). Population-level analysis of gut microbiome variation. Science, 352(6285), 560-564. https://doi.org/10.1126/science.aad3503

Feng, Y., Ramnarine, V.R., Bell, R., Volik, S., Davicioni, E., Hayes, V.M., Ren, S., Collins, C.C. (2019). Metagenomic and metatranscriptomic analysis of human prostate microbiota from patients with prostate cancer. BMC Genomics 20, 146. https://doi.org/10.1186/s12864-019-5457-z

Fuentes, V. (2017). Señalización mediada por receptores tipo Toll: regulación y evasión, UCM, FF, 2-3. https://eprints.ucm.es/56196/

Goodman, B., Gardner, H. (2018). The microbiome and cancer. J. Pathol. 244(5), 667-676. https://doi.org/10.1002/path.5047

Gopalakrishnan, V., Spencer, C. N., Nezi, L., Reuben, A., Andrews, M. C., Karpinets, T. V., Prieto, P. A., Vicente, D., Hoffman, K., Wei, S. C., Cogdill, A. P., Zhao, L., Hudgens, C. W., Hutchinson, D. S., Manzo, T., Petaccia de Macedo, M., Cotechini, T., Kumar, T., Chen, W. S., Reddy, S. M., ... Wargo, J. A. (2018). Gut microbiome modulates response to anti-PD-1 immunotherapy in melanoma patients. Science 359 (6371), 97-103. https://doi.org/10.1126/science.aan4236

Groussin, M., Mazel, F., Alm, E. J. (2020). Co-evolution and Co-speciation of Host-Gut Bacteria Systems. Cell host microbe, 28(1), 12-22. https://doi.org/10.1016/j.chom.2020.06.013

Guarner, F. (2016). Cuando la microbiota intestinal pierde su equilibrio. Impressum health \& science communication. https:/www.gutmicrobiotaforhealth.com/wp-content/uploads/2016/02/20160217_Guarner_dysbiosis-es-1.pdf

Hosoya, N., Miyagawa, K. (2014). Targeting DNA damage response in cancer therapy. Cancer Sci. 105(4). 370-388. https://doi.org/10.1111/cas.12366

Iida, N., Dzutsev, A., Stewart, C. A., Smith, L., Bouladoux, N., Weingarten, R. A., Molina, D. A., Salcedo, R., Back, T., Cramer, S., Dai, R. M., Kiu, H., Cardone, M., Naik, S., Patri, A. K., Wang, E., Marincola, F. M., Frank, K. M., Belkaid, Y., Trinchieri, G., ... Goldszmid, R. S. (2013). Commensal bacteria control cancer response to therapy by modulating the tumor microenvironment. Science, 342(6161). 967-970. https://doi.org/10.1126/science.1240527

Jacobson, A., Yang, D., Vella, M., Chiu, I. M. (2021). The intestinal neuro-immune axis: crosstalk between neurons, immune cells, and microbes. Mucosal Immunol. 14. 555-565. https://doi.org/10.1038/s41385-020-00368-1 
Jaffray D. A. (2012). Image-guided radiotherapy: from current concept to future perspectives. Nat. Rev. Clin. Oncol. 9(12), 688-699. https://doi.org/10.1038/nrclinonc.2012.194

Johnston, E. L., Heras, B., Kufer, T. A., Kaparakis-Liaskos, M. (2021). Detection of Bacterial Membrane Vesicles by NOD-Like Receptors. Int. J. Mol Sci. 22(3), 1005. https://doi.org/10.3390/ijms22031005

Kassam, Z., Lee, C. H., Yuan, Y., Hunt, R. H. (2013). Fecal microbiota transplantation for Clostridium difficile infection: systematic review and meta-analysis. Am. J. Gastroenterol. 108(4), 500-508. https://doi.org/10.1038/ajg.2013.59

Katongole, P., Sande, O.J., Joloba, M., Reynolds, S.J., Niyonzima, N. (2020). The human microbiome and its link in prostate cancer risk and pathogenesis. Infect Agents Cancer 15, 53. https://doi.org/10.1186/s13027-020-00319-2

Kim, Y. S., Kim, J., Park, S. J. (2015). High-throughput 16S rRNA gene sequencing reveals alterations of mouse intestinal microbiota after radiotherapy. Anaerobe 33, 1-7. https://doi.org/10.1016/j.anaerobe.2015.01.004

Knaul, F.M., Arreola-Ornelas, H., Velázquez, E., Dorantes, J., Méndez, O., Ávila-Burgos, L. (2009). El costo de la atención médica del cáncer mamario: el caso del Instituto Mexicano del Seguro Social. Salud Pública De México, 51 Supl. 2, S286-S295. https://saludpublica.mx/index.php/spm/article/view/4897

Liss, M.A., White, J.R., Goros, M., Gelfond, J., Leach, R., Johnson-Pais, T., Lai, Z., Rourke, E., Basler, J., Ankerst, D., Shah, D.P. (2018). Metabolic Biosynthesis Pathways Identified from Fecal Microbiome Associated with Prostate Cancer. Eur. Urol, 74(5) 575-582. https://doi.org/10.1016/j.eururo.2018.06.033

Liu, X., Pu, Y., Cron, K., Deng, L., Kline, J., Frazier, W. A., Xu, H., Peng, H., Fu, Y. X., Xu, M. M. (2015). CD47 blockade triggers T cell-mediated destruction of immunogenic tumors. Nat. Med. 21(10), 1209-1215. https://doi.org/10.1038/nm.3931

Lloyd-Price, J., Abu-Ali, G., Huttenhower, C. (2016). The healthy human microbiome. Genome Med., 8(1), 51. https://doi.org/10.1186/s13073-016-0307-y

Lyon, A.R., Yousaf, N., Battisti, N., Moslehi, J., Larkin, J. (2018). Immune checkpoint inhibitors and cardiovascular toxicity. The Lancet. Oncol. 19(9): e447-e458. https://doi.org/10.1016/S1470-2045(18)30457-1

Ma, J., Zhu, W., Liu, B. (2021). Role of Gut Microbiome in the Outcome of Cancer Immunotherapy. Int. J. Cancer. 149(4). 760-768. https://doi.org/10.1002/ijc.33524

Macfarlane, S., Cleary, S., Bahrami, B., Reynolds, N., Macfarlane, G. T. (2013). Synbiotic consumption changes the metabolism and composition of the gut microbiota in older people and modifies inflammatory processes: a randomised, double-blind, placebo-controlled crossover study. Aliment. Pharmacol. Ther. 38(7), 804-816. https://doi.org/10.1111/apt.12453

Mager, L. F., Burkhard, R., Pett, N., Cooke, N., Brown, K., Ramay, H., Paik, S., Stagg, J., Groves, R. A., Gallo, M., Lewis, I. A., Geuking, M. B., McCoy, K. D. (2020). Microbiome-derived inosine modulates response to checkpoint inhibitor immunotherapy. Science, 369(6510), 1481-1489. https://doi.org/10.1126/science.abc3421 
Flores-Martínez, L. P.; G-Santoyo, I. ; Arriaga-Canon, C.; Jiménez-Trejo, F. J.; Tapia Rodríguez, M.

Mitra, A., Grossman Biegert, G. W., Delgado, A. Y., Karpinets, T. V., Solley, T. N., Mezzari, M. P., Yoshida-Court, K., Petrosino, J. F., Mikkelson, M. D., Lin, L., Eifel, P., Zhang, J., Ramondetta, L. M., Jhingran, A., Sims, T. T., Schmeler, K., Okhuysen, P., Colbert, L. E., Klopp, A. H. (2020). Microbial Diversity and Composition Is Associated with Patient-Reported Toxicity during Chemoradiation Therapy for Cervical Cancer. Int. J. Radiat. Oncol. Biol. Phys. 107(1), 163-171. https://doi.org/10.1016/j.ijrobp.2019.12.040

Neemann, K., Freifeld, A. (2017). Clostridium difficile-Associated Diarrhea in the Oncology Patient. J. Oncol. Pract. 13(1), 25-30. https://doi.org/10.1200/JOP.2016.018614

Nicolaro, M., Portal, D. E., Shinder, B., Patel, H. V., Singer, E. A. (2020). The human microbiome and genitourinary malignancies. Ann. Transl. Med. 8(19), 1245. https://doi.org/10.21037/atm-20-2976

Ohadian Moghadam, S., Momeni, S. A. (2021). Human microbiome and prostate cancer development: current insights into the prevention and treatment. Front Med., 15(1), 11-32. https://doi.org/10.1007/s11684-019-0731-7

Porter, C. M., Shrestha, E., Peiffer, L. B., Sfanos, K. S. (2018). The microbiome in prostate inflammation and prostate cancer. Prostate Cancer Prostatic Dis, 21 (3), 345-354. https://doi.org/10.1038/s41391-018-0041-1

Poutahidis, T., Cappelle, K., Levkovich, T., Lee, C.W., Doulberis, M., Ge, Z., Fox, J.G., Horwitz, B.H., Erdman, S.E. (2013). Pathogenic intestinal bacteria enhance prostate cancer development via systemic activation of immune cells in mice. PloS one, 8(8), e73933. https://doi.org/10.1371/journal.pone.0073933

Puente, J., de Velasco, G. (2019). ¿Qué es el cáncer y cómo se desarrolla? Sociedad Española de Oncología Médica. https://seom.org

Qiu, Q., Lin, Y., Ma, Y., Li, X., Liang, J., Chen, Z., Liu, K., Huang, Y., Luo, H., Huang, R., \& Luo, L. (2021). Exploring the Emerging Role of the Gut Microbiota and Tumor Microenvironment in Cancer Immunotherapy. Front. Immunol. 11, 612202. https://doi.org/10.3389/fimmu.2020.612202

Rai R. C. (2020). Host inflammatory responses to intracellular invaders: Review study. Life Sci. 240, 117084. https://doi.org/10.1016/j.1fs.2019.117084

Rebello, R. J., Oing, C., Knudsen, K. E., Loeb, S., Johnson, D. C., Reiter, R. E., Gillessen, S., Van der Kwast, T., Bristow, R. G. (2021). Prostate cancer. Nat. Rev. Dis. Primers 7(1), 9. https://doi.org/10.1038/s41572-020-00243-0

Ridlon, J. M., Ikegawa, S., Alves, J. M., Zhou, B., Kobayashi, A., Iida, T., Mitamura, K., Tanabe, G., Serrano, M., De Guzman, A., Cooper, P., Buck, G. A., Hylemon, P. B. (2013). Clostridium scindens: a human gut microbe with a high potential to convert glucocorticoids into androgens. J. Lipid Res. 54(9), 2437-2449. https://doi.org/10.1194/jlr.M038869

Rojo, D., Méndez-García, C., Raczkowska, B. A., Bargiela, R., Moya, A., Ferrer, M., Barbas, C. (2017). Exploring the human microbiome from multiple perspectives: factors altering its composition and function. FEMS Microbiol. Rev. 41(4), 453-478. https://doi.org/10.1093/femsre/fuw046

Rosenberg, E., Zilber-Rosenberg, I. (2020). The hologenome concept of evolution: do mothers matter most? BJOG 127 (2), 129-137. https://doi.org/10.1111/1471-0528.15882

Sanchez-Cañizares, C, Jorrín, B, Poole, P.S., Tkacz A. (2017). Understanding the holobiont: the interdependence of plants and their microbiome. Curr. Opin. Microbiol. 38: 188-196. https://doi.org/10.1016/j.mib.2017.07.001 
Sánchez-Quinto, A., Cerqueda-García, D., Falcón, L. I., Gaona, O., Martínez-Correa, S., Nieto, J., G-Santoyo, I. (2020). Gut Microbiome in Children from Indigenous and Urban Communities in México: Different Subsistence Models, Different Microbiomes. Microorganisms, 8(10), 1592. https://doi.org/10.3390/microorganisms8101592

Sender, R., Fuchs, S., \& Milo, R. (2016). Revised Estimates for the Number of Human and Bacteria Cells in the Body. PLoS Biol., 14(8), e1002533. https://doi.org/10.1371/journal.pbio.1002533

Sha, S., Ni, L., Stefil, M., Dixon, M., Mouraviev, V. (2020). The human gastrointestinal microbiota and prostate cancer development and treatment. Investig Clin Urol, 61 (Suppl. 1) S43-S50. https://doi.org/10.4111/icu.2020.61.S1.S43

Shiao, S.L., Chia-Yi Chu, G., Chung, L.W.K. (2016). Regulation of prostate cancer progression by the tumor microenvironment. Cancer Lett. 380(1) 340-348. https://doi.org/10.1016/j.canlet.2015.12.022

Shrestha, E., White, J.R., Shu-Han, Y., Kulac, I., Ertunc, O., De Marzo, A.M., Yegnasubramanian, S., Mangold, L.A., Partin, A.W., Sfanos, K.S. (2018). Profiling the Urinary Microbiome in Men with Positive versus Negative Biopsies for Prostate Cancer. J. Urol. 199(1) 161-171. https://doi.org/10.1016/j.juro.2017.08.001

Sfanos, K. S., Sauvageot, J., Fedor, H. L., Dick, J. D., De Marzo, A. M., Isaacs, W. B. (2008). A molecular analysis of prokaryotic and viral DNA sequences in prostate tissue from patients with prostate cancer indicates the presence of multiple and diverse microorganisms. Prostate, 68(3), 306-320. https://doi.org/10.1002/pros.20680

Sivan, A., Corrales, L., Hubert, N., Williams, J. B., Aquino-Michaels, K., Earley, Z. M., Benyamin, F. W., Lei, Y. M., Jabri, B., Alegre, M. L., Chang, E. B., Gajewski, T. F. (2015). Commensal Bifidobacterium promotes antitumor immunity and facilitates anti-PD-L1 efficacy. Science, 350(6264), 1084-1089. https://doi.org/10.1126/science.aac4255

Suraya, R., Nagano, T., Kobayashi, K., Nishimura, Y. (2020). Microbiome as a Target for Cancer Therapy. Integr. Cancer Ther. 19: 1-11. https://doi.org/10.1177/1534735420920721

Telesford, K. M., Yan, W., Ochoa-Reparaz, J., Pant, A., Kircher, C., Christy, M. A., Begum-Haque, S., Kasper, D. L., Kasper, L. H. (2015). A commensal symbiotic factor derived from Bacteroides fragilis promotes human CD39(+)Foxp3(+) T cells and Treg function. Gut Microbes 6(4), 234-242. https://doi.org/10.1080/19490976.2015.1056973

Touchefeu, Y., Montassier, E., Nieman, K., Gastinne, T., Potel, G., Bruley des Varannes, S., Le Vacon, F., de La Cochetière, M. F. (2014). Systematic review: the role of the gut microbiota in chemotherapy- or radiation-induced gastrointestinal mucositis - current evidence and potential clinical applications. Aliment. Pharmacol. Ther. 40(5), 409-421. https://doi.org/10.1111/apt.12878

van Vliet, M. J., Harmsen, H. J., de Bont, E. S., \& Tissing, W. J. (2010). The role of intestinal microbiota in the development and severity of chemotherapy-induced mucositis. PLoS Pathog. 6(5), e1000879. https://doi.org/10.1371/journal.ppat.1000879 
Flores-Martínez, L. P.; G-Santoyo, I.; Arriaga-Canon, C.; Jiménez-Trejo, F. J.; Tapia Rodríguez, M.

Vétizou, M., Pitt, J.M., Daillère, R., Lepage, P., Waldschmitt, N., Flament, C., Rusakiewicz, S., Routy, B., Roberti, M.P., Duong, C.P., Poirier-Colame, V., Roux, A., Becharef, S., Formenti, S., Golden, E., Cording, S., Eberl, G., Schlitzer, A., Ginhoux, F., Mani, S., ... Zitvogel, L. (2015). Anticancer immunotherapy by CTLA-4 blockade relies on the gut microbiota. Science, 350(6264). 10791084. https://doi.org/10.1126/science.aad1329

Viaud, S., Saccheri, F., Mignot, G., Yamazaki, T., Daillère, R., Hannani, D., Enot, D. P., Pfirschke, C., Engblom, C., Pittet, M. J., Schlitzer, A., Ginhoux, F., Apetoh, L., Chachaty, E., Woerther, P. L., Eberl, G., Bérard, M., Ecobichon, C., Clermont, D., Bizet, C., ... Zitvogel, L. (2013). The intestinal microbiota modulates the anticancer immune effects of cyclophosphamide. Science, 342(6161). 971-976. https://doi.org/10.1126/science.1240537

Wallace, B. D., Roberts, A. B., Pollet, R. M., Ingle, J. D., Biernat, K. A., Pellock, S. J., Venkatesh, M. K., Guthrie, L., O’Neal, S. K., Robinson, S. J., Dollinger, M., Figueroa, E., McShane, S. R., Cohen, R. D., Jin, J., Frye, S. V., Zamboni, W. C., Pepe-Ranney, C., Mani, S., Kelly, L., ... Redinbo, M. R. (2015). Structure and Inhibition of Microbiome $\beta$-Glucuronidases Essential to the Alleviation of Cancer Drug Toxicity. Chem. Biol. 22(9), 1238-1249. https://doi.org/10.1016/j.chembiol.2015.08.005

Walton, G. E., van den Heuvel, E. G., Kosters, M. H., Rastall, R. A., Tuohy, K. M., Gibson, G. R. (2012). A randomised crossover study investigating the effects of galacto-oligosaccharides on the faecal microbiota in men and women over 50 years of age. Br. J. Nutr. 107(10), 1466-1475. https://doi.org/10.1017/S0007114511004697

Wang, A., Ling, Z., Yang, Z., Kiela, P. R., Wang, T., Wang, C., Cao, L., Geng, F., Shen, M., Ran, X., $\mathrm{Su}$, Y., Cheng, T., Wang, J. (2015). Gut microbial dysbiosis may predict diarrhea and fatigue in patients undergoing pelvic cancer radiotherapy: a pilot study. PloS One, 10(5), e0126312. https://doi.org/10.1371/journal.pone.0126312

Williamson, C. W., Sherer, M. V., Zamarin, D., Sharabi, A. B., Dyer, B. A., Mell, L. K., Mayadev, J. S. (2021). Immunotherapy and radiation therapy sequencing: State of the data on timing, efficacy, and safety. Cancer, 127(10). 1553-1567. https://doi.org/10.1002/cncr.33424

Yang, X., Xie, L., Li, Y., Wei, C. (2009). More than 9,000,000 unique genes in human gut bacterial community: estimating gene numbers inside a human body. PloS One, 4(6), e6074. https://doi.org/10.1371/journal.pone.0006074

Yow, M. A., Tabrizi, S. N., Severi, G., Bolton, D. M., Pedersen, J., Australian Prostate Cancer BioResource, Giles, G. G., \& Southey, M. C. (2017). Characterisation of microbial communities within aggressive prostate cancer tissues. Infect. Agent. Cancer, 12, 4. https://doi.org/10.1186/s13027-016-0112-7

Zhang, Z., Tang, H., Chen, P., Xie, H., \& Tao, Y. (2019). Demystifying the manipulation of host immunity, metabolism, and extraintestinal tumors by the gut microbiome. Signal Transduct. Target. Ther. 4, 41. https://doi.org/10.1038/s41392-019-0074-5 